
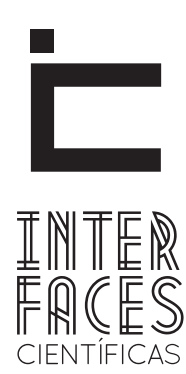

DIREITO

\title{
PARTICIPAÇÃO POPULAR NA GESTÃo dO TERRITÓRIO: PERSPECTIVAS DO DIREITO E DOS ESTUDOS SOCIAIS DA CIÊNCIA E TECNOLOGIA
}

\author{
POPULAR PARTICIPATIONIN THE TERRITORY MANAGEMENT: THE RIGHT PERSPECTIVE AND SOCIAL STUDIES OF SCIENCE AND TECHNOLOGY \\ PARTICIPACIÓN POPULAR EN LA GESTIÓN DEL TERRITORIO: LA PERSPECTIVA CORRECTA Y ESTUDIOS SOCIALES DE CIENCIA Y TECNOLOGía
}

Kelly Cristina Costa $^{1}$

\section{RESUMO}

Este trabalho apresenta a normatização jurídica da participação popular na gestão democrática local, norteada pela Constituição Federal Brasileira de 1988. No entanto, o arcabouço legal, não tem o condão de sozinho estabelecer a efetividade da participação, principalmente direta, da comunidade nas tomadas de decisão na gestão do território. A Constituição Federal depende de legislação complementar, constituinte estadual e legislativo municipal, além dos estudos científicos e técnicos que garantam sua efetividade, objetivando que a administração pública possa adotar, também, tais instrumentos na melhoria de sua esfera de atuação, nesse sentido, o estudo social da ciência e tecnologia vem se mostrando como importante ferramenta no estabelecimento e fomento das discussões técnicas necessárias ao embasamento científico das tomadas de decisão, mas principalmente; tais estudos se voltaram para as questões sociais e surge o envolvimento de atores considerados leigos, capazes, ou não, de contribuir para os debates; produzem a busca de soluções compartilhadas para os problemas comuns. Entretanto, pouco ou nada acontecerá nesse sentido, se a população, a maior interessada na matéria, não estiver atenta na elaboração, fiscalização e cobrança dos seus direitos de cidadania.

\section{PALAVRAS-CHAVE}

Gestão Democrática. Participação Popular. Estudo Social da Ciência e Tecnologia. 


\section{ABSTRACT}

This paper presents the legal regulation of public participation in local democratic management, guided by the Brazilian Federal Constitution of 1988. However, the legal framework does not have the power to own, establish the effectiveness of participation, especially direct, the community in decision in land management. The Federal Constitution depends on complementary legislation, state constituents and municipal legislation, in addition to scientific and technical studies to ensure its effectiveness, in order that the government can adopt also such instruments in improving their sphere of action, in this sense, the social study science and technology is proving to be an important tool in establishing and developing the technical discussions necessary for the scientific basis of decision-making, but mainly; such studies have turned to social issues and appears to involve actors considered laity, able or not to contribute to the discussions; produce the search for shared solutions to common problems. However, little or nothing will happen in this sense, the population most interested in the matter, is not attending the design, inspection and collection of their citizenship rights.

\section{KEYWORDS}

Democratic management, popular participation, social studies of science and technology

\section{RESUMEN}

En este trabajo se presenta la regulación legal de la participación pública en la gestión democrática local, guiada por la Constitución Federal de Brasil de 1988. Sin embargo, el marco legal no tiene el poder de poseer, a establecer la eficacia de la participación, especialmente directa, la comunidad en la toma decisiones en el manejo de la tierra. La Constitución Federal depende de la legislación complementaria, los componentes de la legislación estatal y municipal, además de los estudios científicos y técnicos para garantizar su eficacia, con el fin de que el gobierno puede adoptar también este tipo de instrumentos en la mejora de su esfera de acción, en este sentido, el estudio social la ciencia y la tecnología está demostrando ser una herramienta importante en el establecimiento y el desarrollo de las discusiones técnicas necesarias para la base científica de la adopción de decisiones, pero sobre todo; este tipo de estudios se han dirigido a las cuestiones sociales y parece involucrar a los actores considerados laicos, pueden o no contribuir a los debates; producir la búsqueda de soluciones a problemas comunes compartidos. Sin embargo, poco o nada va a suceder en este sentido, la población más interesado en el asunto, no está asistiendo el diseño, inspección y recaudación de sus derechos de ciudadanía.

\section{PALABRAS CLAVE}

Gestión democrática; la participación popular; los estudios sociales de la ciencia y la tecnología 


\section{INTRODUÇ̃̃̃o}

Aos que consideram Rousseau como o defensor mais radical da soberania popular, cumpre lembrar que ele tenha chegado a concluir ser a democracia o regime perfeito - "para um povo de deuses" (Contrato Social, livro III, cap. 4). No entanto, sem dúvida, sua ideia de que "a soberania não pode ser representada pela mesma razão pela qual ela não pode ser alienada... não sendo, nem podendo ser, seus representantes, mais que seus comissários; não podendo concluir coisa alguma definitivamente" (Contrato Social, livro III, cap. 15), demonstra clara sua posição da não possibilidade de representatividade do povo soberano.

Montesquieu, por sua vez, identificou dentre os grandes vícios da república, o direito a participação dos cidadãos na decisão de matérias para os quais eram totalmente "incapazes", acreditando na representação, como forma vantajosa onde somente os "aptos" e "esclarecidos discutissem os assuntos (De l'esprit des lois, $\mathrm{XI}, 6$ ).

Mas vale lembrar que para Montesquieu, o povo seria capaz de escolher seus representantes "por aspectos que ele não pode ignorar e fatos submetidos ao senso comum" (De l'esprit des lois, II, 3); a necessidade de um limite geográfico "em cada localidade mais importante os habitantes escolherem seu representante", e de que "conhece-se muito melhor as necessidades da cidade em que se vive do que as das demais cidades; e julga-se muito melhor a capacidade de seus vizinhos do que a de outros compatriotas" (De l'esprit des lois, XI, 6), e da relação de confiança entre o povo e seus representantes "a parte que eles tem na legislação deve ser proporcional às outras vantagens que possuem no estado, formando um corpo que tenha o direito de disciplinar as atividades do povo, assim como este tem o direito de disciplinar as suas" (De l'esprit des lois, XI, 6).

A Revolução Francesa; ainda que influenciada pelo pensamento de Rousseau a função legislativa "toda lei que o povo não tenha ratificado em pessoa é nula, não é de fato uma lei”; trouxe o sistema de re- presentação parlamentar exclusiva e a representação abstrata da população pertencente a uma nação. A Declaração dos Direitos do Homem e do Cidadão, de 1971, proclamou que o princípio da soberania reside essencialmente na Nação (art. $3^{\circ}$ ) legitimando o poder do povo.

A evolução social esta ligada ao desenvolvimento técnico e científico, ainda que dessa junção surjam novas controvérsias a serem discutidas, e que, alguns "especialistas" tenham parâmetros claramente definidos, pois, tais controvérsias podem ser capazes de revelar eventos difíceis de serem reconhecidos ao trazerem a discussão causas, interesses, identidades, valores e ações que compõem o corpo social que fazem parte e a falta de informação e os problemas advindos das controvérsias sociais e científicas.

Podem, ainda, a princípio, diminuir a participação popular direta, dadas às dificuldades iniciais de aceitação, sobretudo possível aos que se consideram cientistas, técnicos ou acadêmicos que se veem lidando com atores que necessitam de orientação continuada para desenvolver o tema proposto. Mesma situação é enfrentada ao nos deparamos com discussões ideológicas que ofuscam o pensamento coletivo em detrimento do particular.

Nas tomadas de decisão de âmbito local, que acabam por reverberar níveis administrativos acima do município, as questões técnicas, econômicas, sociais, políticas e ambientais são transdiciplinaridades e abarcam uma solidariedade intergeracional ${ }^{2}$, (sincrônica; diacrônica) imposta a todos (Poder Público e a coletividade) como direito/dever de defender e preservar o "meio ambiente" para as gerações presentes e as futuras.

A descoberta que mesmo nas ciências, as verdades não estão sempre estabelecidas, e a demonstração de experiências onde os cientistas e os cidadãos leigos, conseguiram novas perspectivas, ao se relacionarem a partir de seus questionamentos, e encontrarem jun-

2 CF 88 art. 225 caput. 
tos a solução para os problemas apresentados, conforme demonstrou Callon (1986), nos mostram os novos caminhos que a cidadania, vem percorrendo para além do direito/dever positivo da participação popular em tomadas de decisão de âmbito local, indo aos atores que compõe sua prática, suas relações e contribuições, como o conhecimento científico pode e deve ser aliado a experiência prática dos cidadãos diretamente afetados com a tomada de decisão.

Conforme Latour (1979) tendo a esfera social se livrado dos estigmas que the apuseram aqueles que desejam silenciar a massa, tornou-se fácil reconhecer o caráter humano na prática científica, sua história vívida, suas muitas conexões com o resto do coletivo. 0 autor ainda identifica a necessidade humana de depender de algo que não tem origem humana, mas que não é possível se basear unicamente no que os pesquisadores e descobridores dizem de si mesmos.

A Lei máxima brasileira, nossa Constituição Federal de 1988 (CF/88), em seu art. $1^{\circ}$, norteia que a

República Federativa do Brasil, formada pela união indissolúvel dos Estados e Municípios e do Distrito Federal, constitui-se em Estado Democrático de Direito e tem como fundamentos, entre outros: I - a soberania; II - a cidadania e a III - a dignidade da pessoa humana.

Em seu Parágrafo único: "Todo o poder emana do povo, que o exerce por meio de representantes eleitos ou diretamente, nos termos desta Constituição"

Inovadora e cidadã, a CF/88 atribui genericamente a todas as formações sociais os princípios da solidariedade ou fraternidade, objetivando proteger os interesses de titularidade coletiva ou difusa ${ }^{3}$, destinados à proteção dos interesses transindividuais ${ }^{4}$, mostrando uma grande preocupação com as gerações humanas, presentes e futuras ${ }^{5}$. Amparados no artigo 225, temos a consideração da variável ambiental no processo decisório de políticas de desenvolvimento ${ }^{6}$ (art. 225, § $1^{\circ}$, IV, CF).

3 Código de Defesa do Consumidor, art. 81.

4 Natureza Pública da proteção ambiental: fruição coletiva, bem de uso comum do povo, ligado a realização social.

5 Solidariedade Intergeracional.

6 Declaração do Rio de Janeiro, Princípio 17 , avaliação de impacto ambiental.
A cidadania é adotada no Brasil, de forma indireta, representativa, "exercida pelo sufrágio universal e pelo voto direto e secreto, com valor igual para todos" (CF/88 art.14); e, nos termos da lei, pode ser exercida de forma direta "mediante: I- plebiscito; II - referendo; III - iniciativa popular".

Como exemplos da forma prática da participação popular, temos a Avaliação de Impacto Ambiental que pressupõe a análise prévia dos impactos sociais dos empreendimentos, tendo ainda o Estudo Prévio de Impacto Ambiental (EPIA) ${ }^{7}$, (CF Art. 225, § $1^{\circ}$, IV, VIII) e a audiência pública, descrita na CF art. 74 , §2; 182 , 183, art. 29, XII são a demonstração da participação comunitária direta no planejamento municipal.

Apesar da CF/88 não definir o que é cidadão (ã), ela usa o termo cidadania ${ }^{8}$, e, para seu exercício, temos a participação comunitária, da coletividade ${ }^{9}$ confirmada, por exemplo, nas audiências públicas e no curso dos processos de licenciamento com os Estudos Prévios de Impacto Ambiental ${ }^{10}$ (art. $225 \S 1^{\circ}$, IV) ${ }^{11}$, ou seja, preventivamente, anteriores ao licenciamento ambiental da obra ou atividade, onde obrigatoriamente haverá a participação comunitária na tomada de decisão de interesse local, não afastando possíveis novas exigências e estudos durante a renovação ou revisão das licenças ambientais.

A gestão democrática das cidades brasileiras, sustentada pela Constituição Federal de 1988, regulamentada pela legislação subsequente, consagrada pela soberania popular ${ }^{12}$, condição imprescindível para qualquer tipo de proposta democrática descentralizadora, visando garantir que as tomadas de decisões da administração pública sejam debatidas e deliberadas de forma a realmente garantir o acesso

7 CF 165, I, § $1^{\circ}$; Declaração do Rio de Janeiro, Princípio 17; Decreto 95.733, de 12.2.1998; Decreto 99.274/90, arts. $19 \S 3^{\circ}$ e 23; Lei 6.938/81, arts. $2^{\circ}, 9^{\circ}$, III, Competência CONAMA: Resolução 1/86 (art. $9^{\circ}$ ), 237/97 (art. $\left.3^{\circ}\right), 11 / 86,5 / 87$.

8 art. $1^{\circ}$, II; art. 205; art. 58, $\S 2^{\circ}$; art. $74 \S 2^{\circ}$; art. $5^{\circ}$ LXXI, art. 68 , II, art. $74, \S 2^{\circ}$.

9 CF art 225 caput.

10 Declaração do Rio Princípio 10; Lei 6.938/81 art. 9², VII e XI; Lei 10.650/2003.

11 Em Minas Gerais Resolução Conama 01/86

12 Constituição Federal, art.14, I, II e III. 
a informação ${ }^{13}$, a cooperação e a participação ${ }^{14}$ de todos, é direito fundamental, não sendo meramente uma faculdade, ou ânimo de vontade, já que a participação comunitária é necessária para que qualquer processo de tomada de decisão pública tenha legitimidade, e vários são os mecanismos legais para sua existência, v.g. como instrumento processual o princípio/direito á ação judicial: ação popular ambiental ${ }^{15}$ em favor da coletividade, de aplicação imediata (direito e garantia fundamental); e a ação civil pública ambiental ${ }^{16}$.

A participação popular aparece, ainda, constitucionalmente nos artigos 194, parágrafo único, VII - participação da comunidade nas decisões sobre a seguridade social; art. 198, III - participação da comunidade nas ações e serviços públicos de saúde; art. 204, II - a participação da população por meio de organizações representativas na formulação de políticas de assistência social; no art. 225, caput ao impor ao Poder Público e à coletividade o dever de atuar para defender e preservar o meio ambiente, e, na Lei no $9.784 / 1999$, art. $31, \S \S 1^{\circ}$ e $2^{\circ} ; 32$, sobre a participação comunitária no processo administrativo no âmbito da Administração Pública Federal.

Em sua aplicação efetiva, o Direito Ambiental tem como direito/dever a obrigação de reunir todos ${ }^{17}$ (Poder Público e a coletividade) na construção de um ambiente ecologicamente equilibrado como direito fundamental da pessoa humana (cláusula pétrea) ${ }^{18}$, sendo o direito ao ambiente sadio uma extensão do direito a vida.

A Lei no 10.257/2001, chamada de Estatuto da Cidade, que se refere à questão da política urbana, cujo objetivo é regulamentar os artigos 182 e 183 da Constituição Federal, em seu capítulo IV (arts. 43 a 45), trata da gestão democrática da cidade, externando os dois postulados básicos do Estado Democrático de Direito consagrados na Constituição da República: soberania popular e cidadania.

\footnotetext{
$13 \mathrm{CF} / 88$ art.5 $5^{\circ}$, inciso XXXIII.

14 Declaração do Rio, art. 10

15 art. $5^{\circ}$, LXXIII.

16 art. 129, III; Lei 7.347/85.

$17 \mathrm{CF}$, art. 225, caput.

$18 \mathrm{CF}$, art. $60, \S 4^{\circ}$, IV.
}

$\mathrm{Na}$ tentativa de acompanhar a formação das novas redes humanas, surge o Decreto $n^{0} 8.243 / 2014$, que institui a Política Nacional Social (PNPS) e o Sistema Nacional de Participação Social (SNPS), em que o advento do meio virtual é consagrado (art. $4^{\circ}$, VI; Art. $6^{\circ}$ IX). Entre suas diretrizes estampadas em seu art 18, temos nos incisos: $\mathrm{V}$ - garantia da diversidade dos sujeitos participantes; VII - utilização de ambientes e ferramentas de redes sociais, quando for o caso; IX - sistematização e publicidade das contribuições recebidas.

Dentre as situações verificáveis nessas novas redes, conforme ironicamente previsto pelo humorista húngaro Frigyes Karinthy na década de 1920 (Conto Correntes 1929), onde os graus de separação dos indivíduos são pequenos, a informação é repassada rapidamente, e atualmente, temos o maior acesso de novos atores antes distantes do debate público; o surgimento de necessidades e demandas em comum, coletivas e difusas consideradas legítimas, que podem advir a princípio por meio do Poder Público, na tentativa de ampliar ou renovar seu campo de ação, ou, das ações dos partidos políticos que tentam lidar com os problemas encontrados pela população, ou ainda, de forma espontânea, como vem ocorrendo nas manifestações populares no Brasil, aonde a população aos poucos vai quebrando a delimitação inicial restrita, por exemplo, a círculos políticos, administrações centrais, diretorias e presidências de empresas públicas, podendo trazer a luz controvérsias capazes de auxiliar a realização de possíveis novas conexões, novas investigações, trabalhos técnicos e científicos e novas reflexões e incertezas surgidas durante o debate.

A partir das incertezas, das dúvidas também sociais, em relação às provas incontestáveis trazidas pelas ciências e pelas técnicas, surgem novas investigações, as análises das capacidades de se tomar decisões racionais, enriquecidas com os movimentos sociais que tomam corpo à medida que o debate avança.

Também em relação às incertezas, geradas pelo questionamento das ciências, ainda mais marcantes e necessárias na defesa ao direito inviolável à sadia qualidade de vida, garantida por um ambiente ecologicamente equilibrado ${ }^{19}$, que a legislação ambiental 19 CF 88 art. 225 caput. 
brasileira, abarcou, dentre outros, o princípios a Prevenção ${ }^{20}$, onde os riscos são conhecidos pela ciência, caracterizados pelo perigo concreto e pelas medidas acautelatórias e obrigações mesmo antes da implantação de empreendimento e atividade efetiva ou potencial poluidora; e o princípio da Precaução ${ }^{21}$, onde ocorre a necessidade de gerir riscos ou impactos desconhecidos, o perigo é abstrato, tomado quando a informação científica é insuficiente, inconclusiva ou incerta, havendo indicações de efeitos no ambiente, na saúde de pessoas ou animais, na proteção vegetal, potencialmente perigosos e incompatíveis com o nível de proteção escolhido.

De forma geral, as normas regulamentadoras ambientais podem vir acompanhadas de caráter técnico e científico, já que, por sua natureza necessitam dos estudos da ciência e da tecnologia. Como exemplo, temos a Regularização Ambiental em Minas Gerais ${ }^{22}$, exercida pelo Conselho Estadual de Política Ambiental (COPAM), por intermédio das Câmaras Especializadas, das Unidades Regionais Colegiadas (URC), das Superintendências Regionais de Meio Ambiente e Desenvolvimento Sustentável (SUPRAMS), da Fundação Estadual do Meio Ambiente (FEAM), do Instituto Mineiro de Gestão das Águas (IGAM) e do Instituto Estadual de Florestas (IEF), inicia-se o licenciamento ambiental de forma administrativa pelas SUPRAM's, encarregadas pelos dos processos de licenciamento e Autorização Ambiental de Funcionamento (AAF) de acordo com o Art. $1^{\circ}$ do Decreto Estadual $n^{\circ}$ 44.844/08.

A ordem social ${ }^{23}$ está vinculada ao bem-estar da coletividade, e, para isso, demanda de garantias de obediência às regulações científicas, técnicas, sociais e jurídicas relacionadas com a gestão ambiental do território. Em um trabalho que demanda a participação de diversos atores, com conhecimentos variados, dentre eles os chamados técnicos/cientistas em 20 Lei $\mathrm{n}^{\circ} 6.938 / 81$, art. $2^{\circ}$ incisos II, III, IV, VI, VII, IX e X; art. $4^{\circ}$ incisos III, IV e V.

21 Declaração do Rio Princípio 15, Convenção sobre Mudança Climática art. $3^{\circ}$, Decreto Legislativo 1 , de 03/02/94, CF art. 225,V; Lei 9.605/98 art.57 $\S 3^{\circ}$; Lei $11.105 / 2005$ art. $1^{\circ}$ caput.

22 Deliberação Normativa COPAM (DN 74/04).

23 Art. 192 CF/88. stricto sensu, não é possível considerarmos apenas os critérios técnicos/científicos nas tomadas de decisão que afetam a coletividade, de forma consoante a Collins e Robert Evans (2002), surgindo assim um problema ao se estabelecer as tomadas de decisão públicas baseados somente em explicações técnicas.

Da mesma forma, tais tomadas de decisão não serão aceitáveis se vindas de um público que desconhece completamente as bases mínimas de risco imposto como consequência das decisões das quais farão parte, sob pena de criarem um risco, antes inexistente, agora existente de forma voluntária.

Segundo Collins e Evans (2002), os estudos da ciência mostram que as decisões devem conter a participação de diversos atores, somados aos especialistas certificados. A partir daí, é possível conceber um sistema de planejamento que integra todos ao ambiente em produção.

O desenvolvimento progressivo das relações sociais por meio da constituição de um conhecimento científico (CALLON, 1986), é utilizado na construção de uma rede de relacionamentos entre as entidades sociais e naturais.

No entanto, há que serem observadas a produção simultânea de conhecimento e construção de uma rede de relacionamentos em que entidades sociais e naturais controlem mutualmente quem eles são e o que eles querem (CALLON, 1986, p. 196-223).

Exemplos como os trazidos por Callon (1986), onde a diminuição do estoque de vieiras francesas ocorreu devido a variáveis científicas naturais (inverno rigoroso, aumento no número de predadores) e humanas (aumento do consumo sem atender as necessidades de reprodução), e sua problematização demonstram uma forma de desenvolvimento conjunto de estratégias, após a participação de diversos atores heterogêneos e suas inter-relações, e a mobilização para que tais métodos, pudessem garantir a representatividade da coletividade e o legítimo processo decisório.

Na produção simultânea do conhecimento e construção de uma rede de relacionamentos em que entidades sociais e naturais controlam mutualmente 
quem eles são e o que eles querem. 0 exemplo demonstrado por Callon (1986) mostra que a problematização, em vez de ser uma redução do inquérito a uma formulação simples, toca em elementos, pelo menos parcialmente e localmente, que são partes de tanto o social e os mundos naturais, onde a análise feita pelas ciências sociais em relação a ciência e a tecnologia carregam grandes dificuldades, tendo em vista o envolvimento dos cientistas e engenheiros nas controvérsias técnicas, não levando em conta as estruturas sociais que fazem parte.

Pesquisadores têm o direito de debater detalhes técnicos, mas a análise social e interpretações que eles propõem e discutem podem ser consideradas irrelevantes ou usadas contra eles para criticas suas escolhas. Callon (1986) afirma que a natureza teórica é uma dificuldade, além da metodologia, aja vista o número de autores e de controvérsias sobre explicações sociológicas que podem ser intermináveis e jamais chegar a um consenso.

Ainda segundo Callon (1986), uma maneira de evitar estas dificuldades seria voltar ao início e simplesmente negar possibilidade de fornecer uma definição sociológica da ciência e da tecnologia. Outra possibilidade conserva e alarga as recentes conclusões da sociologia da ciência e da tecnologia. É discutível a explanação sociológica das controvérsias científicas e técnicas, tão quanto o conhecimento e os objetos que ela representa. A dificuldade teórica nasce a partir do momento em que se aceita que as duas ciências, sociais e naturais, são igualmente incertas, ambíguas e discutíveis, não sendo possível terem regras diferentes na análise.

Callon (1986) trata ainda da Reflexividade como uma extensão para as ciências sociais, e a análise que estas oferecem para a construção de consenso no âmbito das ciências naturais. Como a natureza, a ciência não pode ser invocada para explicar a resolução da controvérsia e da construção do conhecimento firme. Ele acertadamente afirma que não existem garantias, afinal as explicações devem ser questionadas, mas isso não significa que o consenso provisório não pode ser alcançado.
Em outra mão, ainda que os métodos participativos de deliberação alcancem os objetivos para os quais foram criados, dentre eles a garantia da participação de todos, deve-se considerar os diversos atores, suas experiências e conhecimentos para atuar horizontalmente nas ferramentas participativas, e a fixação de alguns formalismos como limites para a extensão e prazo da participação ampla, evitando que a ampliação do debate se torne irracional, não atinja seus objetivos e ainda extrapole o calendário normalmente estabelecido pela esfera política.

Um mecanismo deliberativo forte ocorre com a mediação entre o diálogo dos diversos atores, dentro de uma política de educação formal e informal, construindo juntos as técnicas necessárias as deliberações públicas mais eficazes de acordo com o contexto da região de influência e os conhecimentos adquiridos pela troca de conhecimento entre os cientistas e os chamados "especialistas leigos" cuja experiência não foi reconhecida pela certificação, mas são encontrados dentro dos diversos grupos participativos.

Analogamente, tendo tais espaços de deliberação a constituição do que Callon chamou de "Fórums Híbridos" ${ }^{24}$, devemos considerar estes espaços públicos os locais onde as questões podem ser levantadas e debatidas, de forma difusa e coletiva, por grupos heterogêneos, com abordagens distintas, incluindo a comunidade, especialistas, políticos, técnicos, leigos, e, a partir das discussões, possam ocorrer a emersão de opções técnicas, científicas, políticas, sociais, ambientais e econômicas de forma coletiva, envolvendo pessoas, grupos, instituições e porta-vozes diversos, tornando esses fóruns uma resposta às incertezas advindas das tecnociências. 0 autor afirma ainda que a sociedade pode ser tão incerta e imprevisível como as entidades não-humanas com as quais tem escolhido compartilhar seu destino.

Inicialmente o grupo deve ser orientado a analisar e refletir sobre suas próprias capacidades, limitações, diferenças, potencialidades e conhecimentos e a partir daí determinar as melhores formas, ações, e condições para que os diversos saberes sejam com-

24 Hybrid Foruns. 
partilhados, levando todos os atores a se tornarem experientes contributivos já que em termos de experiência, todos, ainda que sem qualificações formais possa absorver conhecimento a partir da experiência interacional, desde que receptivos a outras linguagens e voltados a atender os interesses comuns da comunidade.

Mesmo não sendo a única trajetória possível, tendo em vista algumas incertezas perdurem no tempo e no espaço, para que possamos identificar o risco e as possíveis estratégias de enfrentamento, após a análise de todas as opções apresentadas e de hipóteses de solução possíveis surgidas, o tomador de decisões deve reunir todos os atores participativos do processo decisório na tentativa de passarmos da incerteza radical á suspeita, e, desta para a presunção e algumas vezes a provas.

Como já estabelecido, não é possível realizar um tomada de decisão tendo por base um único segmento social, resta saber se podemos categorizar cada conhecimento, usando conhecimento e experiência como categorias estabelecidas pelo pesquisador/ modelador, dados primários e secundários espelhados a partir da classificação de Collins ${ }^{25}$ em: pouco experiente - conhecimento insuficiente para realizar uma análise a partir de critérios técnicos e sociais apresentados em ambientes participativos públicos; experiente interacional - possui experiência suficiente para interagir curiosamente com os participantes e realizar análises confiantes para deliberar; experiente contributivo - experiência suficiente para contribuir seja de forma científica, técnica, social e conhecimentos, ainda que informais desde que relativos aos temas em questão. Nos moldes do autor, é possível categorizar em: 1. pouco experiente; 2 . experiente interacional e 3. experiente contributivo.

No entanto, há que se abrirem considerações aos casos que se distanciam da media (outliers) das realidades do ser humano médio, que pode desconhecer completamente as práticas jurídicas, legislativas e administrativas aqui consideradas, que podem se distanciar muito da média de conhecimento necessário ao exercício da cidadania.

25 Third Wave
O envolvimento de profissionais citadinos e poder público, ligados ao território, como fontes de informação, aliados a métodos de pesquisa, é base importante de dados primários e secundários que tem obrigação de serem capazes de reproduzir a realidade local.

Os debates permitem a investigação e a multiplicidade de possíveis soluções a determinados obstáculos vindas da pluralidade dos vários pontos de vista, a mobilização de diferentes atores técnicos e sociais, o desenvolvimento de soluções alternativas, a argumentação e a participação popular, a clareza e transparência nas tomadas de decisão, principalmente quando existem desconhecimentos e incertezas, tornando possível a reformulação dos impedimentos e objetivos, constituindo um processo de aprendizagem coletiva.

As relações entre especialistas e leigos, como também entre diferentes grupos deve estar embasada no fato de que todos possuem formas específicas de conhecimento, indo para além da defesa de interesses egoísticos, redefinindo as identidades e abrindo caminho para novas alianças e compromissos, resultando em mais conhecimento, em uma construção, onde leigos intervém em questões técnicas, cientistas das chamadas ciências frias se abrem as questões sociais, a população é convocada a se manifestar diretamente, sem a presença de seus porta-vozes, envolvida no debate político, em um sistema de cooperação entre os diversos atores.

Conforme Rajao e Hayes (2009) as concepções de controle, tradicionalmente utilizadas, atuam como modelos culturais para a estruturação de novas ações e certo conjunto de estruturas, limitando as possibilidades de ação (FLIGSTEIN; BRANTLEY, 1992, p. 287), podendo também ser entendidas como uma lógica institucional de conjuntos e práticas e simbólicos materiais de construção disponível aos indivíduos, de modo a fazer sentido em seu ambiente (FRIEDLAND; ALFORD, 1991, p. 248).

As práticas e ações desejáveis devem ser buscadas em primeiro lugar. Após essa análise, é preciso conhecer os arranjos institucionais estabelecidos, a infraestrutura social e cultural associada a eles e a partir daí tentar estabelecer melhorias institucionais. 
A demonstração empírica dos autores Rajão e Hayes (2009), enfoca a contestada, conflituosa e emergente natureza da institucionalização, cujas mudanças desejadas não ocorrem de forma linear, levando de encontro concepções de controle concorrentes, atendendo às maneiras pelas quais as estruturas de poder entre atores poderosos podem ser tomadas como certas (ROBEY; HOLMSTROM, 2001; SEO; CREED, 2002), como Blackler e Regan (2006).

É preciso analisar as possibilidades técnicas, científicas e sociais na mesma medida para que gerem os efeitos jurídicos esperados. Ao mesmo tempo, este esquema mantem a simetria entre as controvérsias que pertencem à natureza e aquelas que pertencem à sociedade (CALLON, 1986).

A participação de todos, sendo estes realmente capazes de tomar decisões públicas, possui contextos capazes de ser correlacionados entre Tecnologia da Informação (TI) na medida em que esta demonstra ser capaz de oferecer informações novas, modos alternativos de compreensão e ações envolvendo a realidade a ser abordada, a determinação e a padronização sequencial de tarefas (KALLINIKOS, 2004).

A partir da consagração efetiva da participação popular, onde realmente a comunidade se envolve e participa das tomadas de decisões, os atores envolvidos desenvolverão confiança e a relação entre administrados e administradores (governados e governantes) tende a melhorar, propendendo à criação de uma fidelização ideológica, facilitadora das ações em benefício comum, melhor recepcionadas por se tratarem de ideias criadas por meio de opiniões compartilhadas, desenvolvidas em parceria, onde os integrantes serão ainda cidadãos disseminadores desta gestão compartilhada em rede.

O aumento da participação aberta ao público, que a principio pode por alguns ser considerado ignorante, capaz de tumultuar ou mesmo atravancar as tomadas de decisão ao levantar controvérsias, dúvidas, e necessitar de opções variadas para seu convencimento, se mostra cada vez mais importante em momentos de precaução, apresentando evolução significativa com o passar do tempo de convi- vência do grupo encarregado da tomada de decisão pública, se este se mostra interessado e participativo, sendo possível e buscado no decorrer do processo de tomada de decisão em matéria ambiental, que aconteça, somado ao debate, um processo de aprendizagem horizontal, se essa aprendizagem ocorrer nos vários sentidos: população aprendendo com os acadêmicos, cientistas e técnicos, técnicos e cientistas com a população na medida que convivem com os moradores e trabalhadores locais, conhecem suas histórias e necessidades.

\section{REFERÊNCIAS}

BLACKLER, F. \& REGAN, S. (2006) Institutional reform and the reorganization of family support services. Organization Studies, 27(12): 1843-1861.

\section{BRASIL. Presidência da República. Constituição}

Federal Brasileira de 1988. Disponível em: <http:// www.planalto.gov.br/ccivil_03/constituicao/ ConstituicaoCompilado.htm>. Acesso em: $14 \mathrm{dez}$. 2015

BRASIL. Presidência da República. Lei no 9.784, de 29 de janeiro de 1999. Disponível em: <http://www. planalto.gov.br/ccivil_03/LEIS/L9784.htm>. Acesso em: 13 dez. 2015.

BRASIL. Presidência da República. Lei n⿳0 10.257, de 10 de julho de 2001. Disponível em: <http://www. planalto.gov.br/ccivil_03/leis/LEIS_2001/L10257. htm>. Acesso em: 9 dez. 2015.

BRASIL. Presidência da República. Decreto n 8.243, de 23 de maio de 2015. Disponível em: <http://www. planalto.gov.br/ccivil_03/_Ato2011-2014/2014/ Decreto/D8243.htm>. Acesso em: 9 dez. 2015.

CALLON, Michel. Some elements of a sociology of translation: domestication of the scallops and the fishermen of St Brieuc Bay, First published. In: 
LAW,J. Power, action and belief: a new sociology of knowledge? London: Routledge, 1986. p.196-223.

COLLINS, H.M.; EVANS, Rober. The Third Wave of Science Studies

Studies of Expertise and Experience. Social Studies of Science, v.32, n.2, abr. 2002. p.235-296.

FIUZA, César, Direito civil: curso completo. 10.ed. Revista, atualizada e ampliada. Belo Horizonte: Del Rey, 2007.

FLIGSTEIN, Neil and BRANTLEY, Peter. 1992. “Bank Control, Owner Control or Organizational Dynamics: Who Controls the Modern Corporation." American Journal of Sociology. 98:280-307.

FRIEDLAND, Roger and ALFORD, R. Robert. 1991. 'Bringing society back in: Symbols, practices, and institutional contradictions,' in The New Institutionalism in Organizational Analysis, ed. Walter W. Powell and Paul J. DiMaggio, pp. 232-263. Chicago: University of Chicago Press.
MILARÉ, Édis, Direito do ambiente: a gestão ambiental em foco - doutrina, jurisprudência, glossário/ Édis Milaré; prefácio Ada Pellegrine Grinover. 7.ed. rev., atual. e reform. São Paulo: Revista dos Tribunais, 2011.

MORAES, Alexandre de. Direito Constitucional. 16.ed. São Paulo: Atlas, 2004.

ROBEY, D., and HOLMSTRÖM, J (2001). Transforming Municipal Governance in Global Context: A Case Study of the Dialectics of Social Change. Journal of Global Information Technology Management, 4(4) October 2001.

SEO, M-G., and CREED, W.E.D. , "Institutional Contradictions, Praxis, and Institutional Change: A Dialectical Perspective," Academy of Management Review, 27 (2002), 222-247

WOOLGAR, Latour. Vida de Laboratório. 1979. 